\title{
THE FOURTH WORLD FERTILIZER CONGRESS
}

$T^{T}$ is generally believed that nitrogen is a key element in crop production. This is evident from the figures in Table 1, showing the yield in kilograms in different countries expected for an application of $1 \mathrm{kgm}$. of plant nutrient:

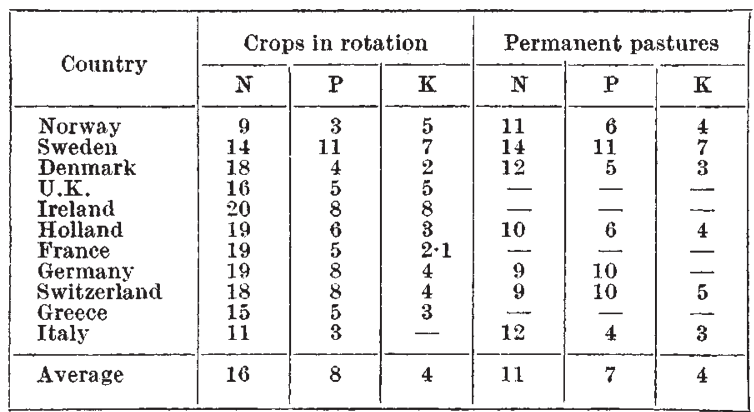

In the Oxford Economic Atlas of the World (Oxford University Press, 1959) the following increased yields per kilogram of nitrogen are recorded:

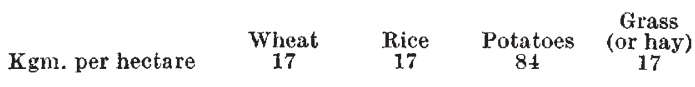

The Indian Council of Agricultural Research has reported that the average production of rice in India is ten times the amount of nitrogen applied. The United Nations Korean Reconstruction Agency has stated that $1 \mathrm{kgm}$. of nitrogen as ammonium sulphate produces $12-14 \mathrm{kgm}$. of brown rice and $14-28 \mathrm{kgm}$. of rough barley in South Korea. Moreover, $1 \mathrm{kgm}$. of phosphate as superphosphate can yield 4-18 kgm. of brown rice. In the United States large amounts of fertilizers have been applied in special cases and the results show a big response to nitrogen, but the responses to phosphate and potash are smaller. Doses in amounts larger than $200 \mathrm{lb}$. of nitrogen or phosphate or potassium per acre show a depressing effect in ordinary soils, but in soils of prairie lands naturally rich in humus, beneficial results are obtained with heavy doses of fertilizers.

Because of the importance of fertilizers in crop production, the world fertilizer industry is well organized by the Intermational Confederation of Engineers and Technicians of Agriculture (C.I.T.A.) at the International Centre of Chemical Fertilizers (C.I.E.C.), Zurich. During May 9-12, the fourth World Fertilizer Congress, organized by the International Centre, met in Opatija on the Adriatic coast of Yugoslavia, under the presidency of Prof. S. Nikolic of Belgrade. Some 290 scientists, industrialists and technicians from twenty-eight countries met to consider six general reports and sixty-five special communications. At this Congress, besides French, English and German, Russian and Yugoslav were also recognized as official languages.

Prof. Nikolic gave an account of the soils of Yugoslavia and the application of fertilizers, micronutrients and organic matter. Prof. M. R. Braconnier, of Paris, reported on fertilizer production and consumption, and stated that in 1958-59, 8.75 million tons of nitrogen, 9.03 million tons of phosphate and 7.88 million tons of potassium were produced by the world fertilizer industries, and the average
$\mathrm{N}: \mathrm{P}_{2} \mathrm{O}_{5}: \mathrm{K}_{2} \mathrm{O}$ ratio of fertilizers applied has shifted from $1: 3.85: 0.77$ in 1900 to $1: 1.03: 0.9$ in 1958 59. In Holland the ratio is $1: 0.5: 0.7$. Prof. $Y$. Coic, of Versailles, discussed the adaptation of fertilizers by cultivated plants. Prof. L. Schmidt, of Darmstadt, discussed the experimental results obtained by compound fertilizers and trace-elements. The influence of irrigation on mineral fertilization was dealt with by Prof. L. Cavazza, of Italy. The application of radioisotopes was introduced by Prof. A. C. Schuffelen, of Holland; papers on work with phosphorus-32 carried out in Italy, Germany, Hungary, Poland and Yugoslavia were given.

The functions of light, temperature, acidity, coatings on fertilizers and humus in the absorption of nutrients by plants were discussed in several papers.

From a survey of crop production and fertilizer application in different countries, it appears that in countries not using large amounts of fertilizers the nitrogen response to cereals is very marked; the law of diminishing return is in operation in Holland, Belgium and Norway, where large amounts of nitrogen are applied. But in Japan, China and Taiwan, where composts and other plant and animal wastes are utilized along with fertilizers, better crop yields per unit nitrogen are still obtained. In the United States, yields of wheat and corn are increased by producing organic matter through rotations.

Approximately 1,000 million tons of cereals, 700 million tons of pulses, potatoes, vegetables, sugars, etc., are being produced annually in the world, and the world grassland production is about 1,600 million tons. Hence assuming the yield is 15 times the nitrogen application, the production of the world's food, fodder and fibre requires approximately 250 million tons of available nitrogen. It has been already stated that the industrial supply of nitrogen is only $8 \cdot 75$ million tons; legumes contribute 5 million tons and precipitation 7-10 million tons of nitrogen. Hence the world soil humus is the chief supplier of crop nitrogen. It is well known that the recovery of nitrogen by crops is smaller than that of phosphate and potash, chiefly due to loss of nitrogen as nitrogen gas in the processes of nitrate formation from manures and fertilizers, and this loss of nitrogen is retarded by organic matter and minerals. Experiments have shown that all nitrogenous fertilizers and manures when applied to land intensify the oxidation of soil humus due to the formation of nitrates in the soil. Organic matter such as straw, plant residues, grasses, etc., when incorporated in soils, not only improve the physical properties of the soil but also fix atmospheric nitrogen and protect the soil nitrogen and increase the humus capital and this is aided by different calcium phosphates. The world reserve of phosphate rocks is of the order of 21,000 million tons and its present utilization is 30 million tons annually. Moreover, the expanding world steel industry is supplying large amounts of basic slags rich in phosphate, lime, magnesia, manganese, copper, vanadium and other useful nutrients. Hence increased utilization of these cheap phosphates incorporated with organic matter could go a long way towards meeting the world-wide lack of nitrogenous fertilizers.
N. R. DHaR 